\title{
POST-TETANIC POTENTIATION OF MYOTATIC REFLEXES IN MAN
}

\author{
KARL-ERIK HAGBARTH
}

\author{
From the Department of Clinical Neurophysiology, the University Hospital, Uppsala, Sweden
}

Hoffmann originally described how an electric shock to the tibial nerve in man evokes not only a motor response in the calf muscles but also a wellsynchronized reflex response with a latency of about $30 \mathrm{msec}$. This late response, which he identified with the stretch reflex, was shown to have the following characteristics (Hoffmann, 1918, 1922: Hoffmann and Keller, 1928): (a) It appears only in muscles supplied by the stimulated nerve; (b) it can be evoked by shocks which are subliminal for motor axons and it tends to be blocked at stronger stimulus strengths (by antidromic impulses in motor axons); (c) it is conducted in afferent fibres of high velocity and its central delay is short enough to indicate a monosynaptic path; (d) it is facilitated by a voluntary contraction of the muscle involved and obliterated by a contraction of its antagonist. Hoffmann also claimed that reflexes with these characteristics are not specific for the calf muscles; they do not appear in other muscles of the extremities, however, unless facilitated by voluntary contraction.

Many of Hoffmann's observations have been confirmed by other workers (Magladery and McDougal, 1950; Magladery, Porter, Park, and Teasdall, 1951; Schenck, 1951: Paillard, 1955) but Magladery and McDougal (1950) made a distinction between the reflexes appearing in the calf muscles (which they termed $\mathrm{H}$-reflexes) and the smaller and more variable late deflections appearing in response to motor nerve shocks in the peroneal muscles of the leg and in the small muscles of the hand and foot (F-waves). They claimed that the F-wave, contrary to the Hreflex, cannot be depressed by increasing the intensity of the stimulus and they deduced that it is a reflex conducted in afferent fibres which are slower than the motor axons. Teasdall, Park, Languth, and Magladery (1952) made the additional observation that the $F$-waves in distal muscles were substituted by typical H-reflexes in a number of patients with upper motor neurone signs due to lesions involving the lower part of the brain-stem or the spinal cord.

The reflex nature of the F-wave was doubted by Dawson and Merton (1956) who studied these responses in ulnar hand muscles and concluded that they represent recurrent discharges from motor neurones. Johns, Grob, and Harvey (1957), however, found typical $\mathrm{H}$-reflexes instead of $\mathrm{F}$-waves in hypothenar muscles of normal adult subjects and Thomas and Lambert (1960) reported the regular occurrence of $\mathrm{H}$-reflexes in hypothenar muscles of newborn infants.

Most authors (Magladery et al., 1951; Hoffmann, 1952; Paillard, 1955; but cf. also Magladery and Teasdall, 1958) emphasize the analogy between the H-reflex in man and the monosynaptic stretch reflex so thoroughly analysed in animal experiments (Lloyd, 1943, 1946; Granit, 1955). The monosynaptic reflex can be easily potentiated by tetanization of the muscle nerve (Lloyd, 1949, 1959; Eccles and Rall, 1951) and, according to F. A. Hoffmann (1952), the phenomenon can also be demonstrated in man, even though the degree of change produced is quite limited. The present study started as a search for such potentiation and the experiments showed that the H-reflex, the simultaneous reciprocal inhibition, and also the mechanically evoked stretch reflex (Achilles and patellar reflexes) can be potentiated. It was also found that the F-waves in the small hand muscles and in the peroneal muscles were often substituted by typical H-reflexes during the period of post-tetanic potentiation.

\section{METHODS}

The author was the subject in all the records illustrated, but the principal results have also been demonstrated in other subjects without any signs of neurological disease. One of the upper or lower extremities was supported comfortably in a convenient position. Peripheral nerve trunks were stimulated by cathodal pulses with a duration of 0.5 to $1 \mathrm{msec}$. The cathode was either a pad electrode placed on the skin over the nerve or a steel needle with the tip close to the nerve trunk. The large anode was placed on the opposite side of the extremity. An accurate control of the intensity of the nerve stimuli was often difficult to obtain since a slight displacement of the cathode in relation to the nerve could not always be avoided during the course of an experiment. Such uncontrollable variations often made it necessary to rep zat an experiment 
several times with alternate surface- and needle-electrodes before valid conclusions could be drawn.

Muscle action potentials were usually led off by paired surface electrodes or by bipolar needles, insulated except for the tips. Coaxial needles were used in occasional attempts to record from more circumscribed areas in the musculature. The amplified potentials were displayed on a dual-beam oscilloscope and superimposed records were photographed.

Pre- and post-tetanic test stimuli were presented at intervals of 2 to $5 \mathrm{sec}$. The frequency of the tetanus was varied within a range of 100 to $500 / \mathrm{sec}$. and the duration was usually 10 to $60 \mathrm{sec}$. The first test stimulus in the post-tetanic series occasionally fell within the first second after the tetanus, but these very early post-tetanic events have not been systematically studied. The intensity of test stimuli and tetanus was varied independently.

Tendon reflexes were elicited by hand with a specially designed reflex hammer which fell from a certain height on a metal plate attached to the tendon. The contact between the hammer and the plate closed an electrical circuit and triggered the sweep.

\section{RESULTS}

H-REFLEXES IN VARIOUS MUSCLES DURING RELAXATION AND VOLUNTARY CONTRACTION The results confirm Hoffmann's original finding that most muscles in the extremities with the exception of those of the calf do not show any typical H-reflexes as long as they are in a state of complete relaxation (cf. also Johns et al., 1957). Fig. 1, A1, shows the response in the relaxed thenar muscles to single median nerve shocks of increasing strength in the wrist region. The initial

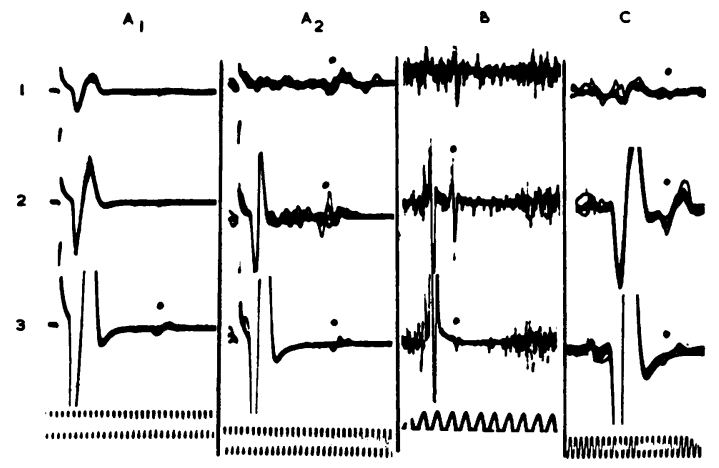

FIG. 1. Action potentials recorded from thenar muscles: A, shock to median nerve above wrist, tibialis anticus: $\mathrm{B}$, shock to peroneal nerve at capitulum fibulae and hypothenar muscles; $\mathrm{C}$, shock to ulnar nerve at elbow. Nerve shocks of increasing strength (1-3) during relaxation (A1) and voluntary contraction (A2, B, C). Recording with surface electrodes from hand muscles, with bipolar needles from tibialis anticus. Late deflection indicated by point. Time in A and C 500/sec., in B 50/sec. Three to five beams superimposed in each record. response ( $\mathrm{M}$-wave, caused by the motor volley) is gradually accentuated and when it has reached approximately maximal amplitude there also appears a small and variable deflection with a much longer latency. Similar results were obtained when stimulating the ulnar nerve and recording from the relaxed hypothenar muscles, or when stimulating the peroneal nerve and recording from the relaxed tibialis anticus or extensor digitorum brevis. As a rule, the late small deflections did not appear until the stimuli were maximal or supramaximal for the motor fibres and they are apparently identical with the F-waves described by Magladery and McDougal (1950).

A slight or moderate voluntary contraction of the muscle concerned often changed the characteristics of the late deflections so that they could not be distinguished from typical $\mathrm{H}$-reflexes. This change was most pronounced in the thenar muscles and in the tibialis anticus where during contraction the late deflection often appeared at a lower threshold than the M-wave; it reached a fairly high amplitude and was suppressed by maximal or supramaximal stimuli (Fig. 1, A2 and B). The change was less obvious in the hypothenar muscles and in the extensor digitorum brevis since here the $\mathrm{M}$-wave, also during contraction, regularly had a lower threshold than the late deflection (Fig. 1C).

A closer study of the records shows that the late deflection in the contracting thenar muscles, following a supramaximal stimulus (A2, lowest record), has approximately the same appearance as the F-wave seen in the relaxed muscle ( $\mathrm{Al}$, lowest record). They both have the same latency which is a few msec. longer than that of the low threshold H-reflex (A2, upper records) but the $\mathrm{H}$-reflex potential has such a long duration that its later components fall within the same time interval as the relatively short F-wave. The question arises whether the late deflection in the lowest $\mathrm{A} 2$ record should be identified with the F-wave in the relaxed muscle or whether it should be regarded as a rudimentary $\mathrm{H}$-reflex, partially blocked by the antidromic motor volley. Both alternatives may be correct since one cannot exclude that the F-wave in fact consists of the later components of the $\mathrm{H}$-reflex which at high stimulus intensities escape the blocking influence of the antidromic motor volley. The blocking influence of a supramaximal nerve shock is also seen as an early suppression of the voluntary activity which immediately follows the large $\mathrm{M}$-wave in the lowest records A2 and B.

The H-reflexes recorded from the contracting thenar muscles and the tibialis anticus were small in comparison with the large $\mathrm{H}$-reflexes appearing in surface recordings from the calf muscles when the tibial nerve was stimulated. Surface electrodes 


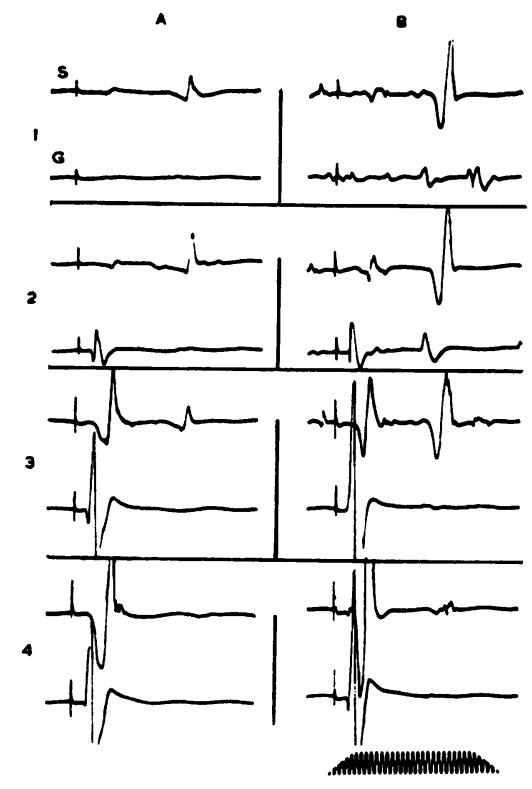

FIG. 2. Simultaneous recording with coaxial needle electrodes from soleus (upper beam) and gastrocnemius med. (lower beam). Shocks of increasing strength (1-4) to tibial nerve in popliteal fossa during relaxation (A) and voluntary contraction of the calf muscles (B). Time 500/sec.

applied on the calf, however, are likely to record the activity from both the gastrocnemius and the soleus muscle and consequently such records do not indicate from which of these muscles the large H-reflexes are derived. Simultaneous recordings from one coaxial needle electrode in the gastrocnemius and another in the soleus showed that the H-reflex is constantly more pronounced in the latter muscle. Fig. 2 shows a typical result of such an experiment where the intensity of the shock on the tibial nerve (in the popliteal fossa) was gradually increased (records 1-4). In the first trial (A) when the muscles were relaxed, the soleus (upper beam) responded to the weak stimuli with a moderate $\mathrm{H}$-reflex (1-2) which was obliterated at high stimulus strengths (3-4), while the gastrocnemius (lower beam) showed no reflex at all. In the next trial (B) a weak voluntary contraction was maintained in both muscles and now the H-reflex in the soleus was greatly facilitated while a low-threshold reflex also appeared in the gastrocnemius. The latter was always much smaller than the reflex in the soleus but it showed the characteristic features of an H-reflex since it had a low threshold and was obliterated at high stimulus strengths. It may be concluded that, as far as the 3
H-reflex is concerned, the gastrocnemius does not differ very much from other muscles of the extremities. The H-reflex in the soleus, however, is exceptional because of its high amplitude and because it also appears during relaxation. These findings agree with the facts that the soleus in cats gives a better stretch reflex than the gastrocnemius (Denny-Brown, 1929) and that soleus motoneurones are especially susceptible to gamma-loop activation (Eccles, Eccles, and Lundberg, 1957).

POST-TETANIC POTENTIATION OF H-REFLEXES In these experiments it was desirable to avoid the blocking influence of the antidromic motor volley and consequently the test $\mathrm{H}$-reflexes were elicited by nerve stimuli subliminal for the motor axons. The upper three records in Fig. 3A show the control amplitude of the $\mathrm{H}$-reflexes in the relaxed soleus, elicited at 5-sec. intervals by weak test shocks applied on the tibial nerve in the popliteal fossa. The following tetanic stimulation of the nerve had a frequency of $200 / \mathrm{sec}$. and duration of $15 \mathrm{sec}$. and it was strong enough to cause a forceful tetanic contraction of the calf muscles. As shown by Fig. 3A this tetanus caused an enduring enhancement of the test $\mathrm{H}$-reflexes. They reached a maximal amplitude about $10 \mathrm{sec}$. after the end of the tetanus and then gradually declined towards the control level during the next 35 seconds. Fig. 3A does not show the events during the first seconds after the tetanus but it was often observed that during this period the $\mathrm{H}$-reflexes were suppressed below the control level.

A similar post-tetanic potentiation was seen in the thenar muscles (Fig. 3B) and in the tibialis anticus (Fig. 3C). In these muscles a voluntary contraction was maintained in order to get a maximal facilitation of the initial control reflexes, and attempts were made to keep this contraction at the same level during the post-tetanic period also. This constancy of the voluntary effort was important when determining the time course of the potentiation, for the amplitude of the potentiated $\mathrm{H}$-reflex could be influenced by voluntary contractions in a way similar to the control reflexes. Thus, an inhibition evoked by a voluntary contraction of an antagonist was often potent enough to eliminate the $\mathrm{H}$-reflexes, even during the period of maximal post-tetanic potentiation. A short inhibition of this kind, however, was followed by a reappearance of potentiated reflexes, which indicates that the inhibition concealed rather than interfered with the potentiation process. The potentiation could in a similar way be concealed by a temporary increase of the stimulus strength which caused a blocking of the reflex.

It was occasionally noted that the potentiation of the H-reflexes was accompanied by an involuntary 
A
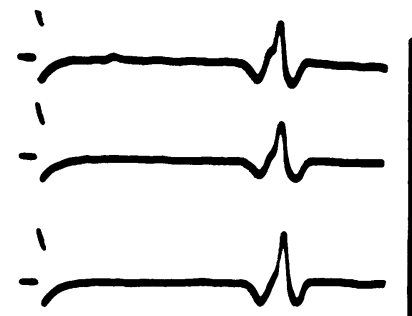

15 SEC. 200
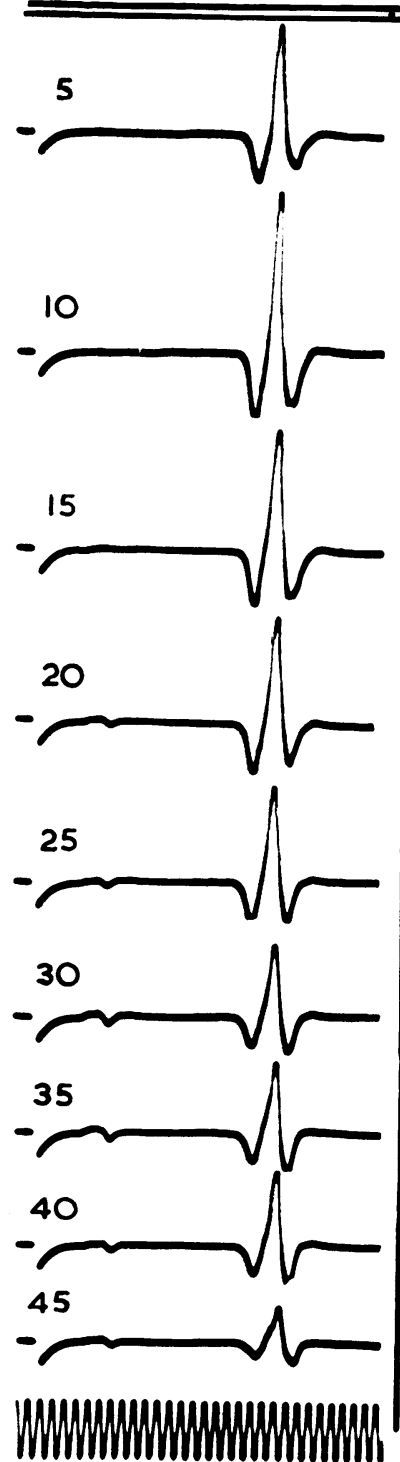

B

C
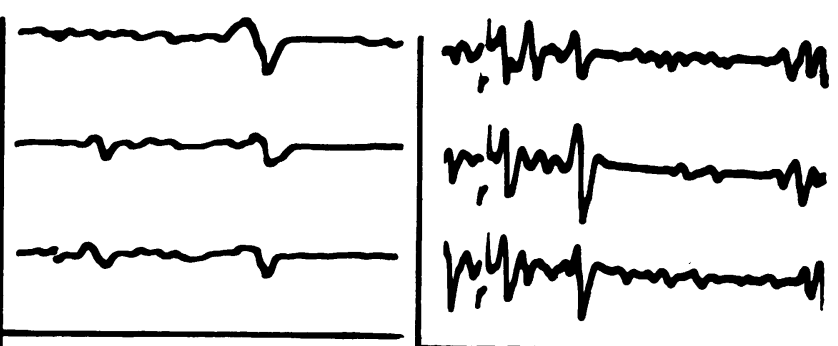

20 SEC. 100
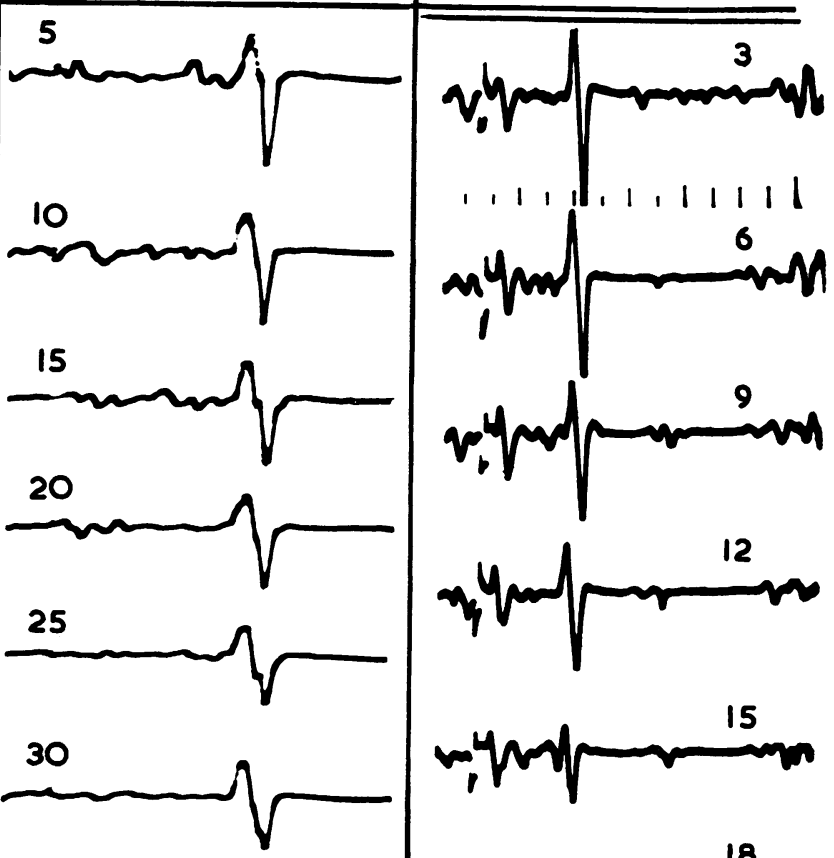

35
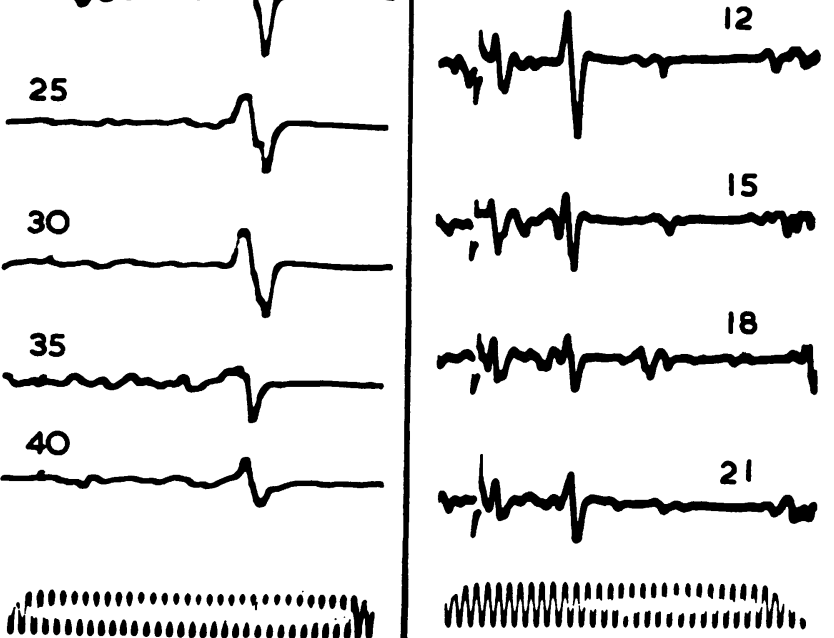

15

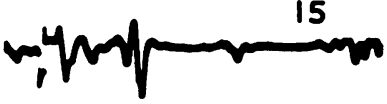

18
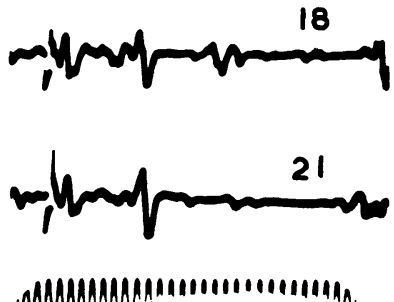

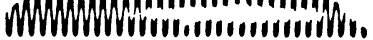

FIG. 3. H-reflexes recorded with surface electrodes from soleus (A, shocks to tibial nerve in popliteal fossa), thenar muscles (B, shocks to median nerve above wrist), and tibialis anticus (C, shocks to peroneal nerve at capitulum fibulae). Weak nerve shocks of constant strength repeated at regular intervals before (upper three records) and after intense nerve tetanization (duration and frequency indicated). Numbers on post-tetanic records indicate seconds after tetanus. Time in A and B 500/sec.. in C 200/sec. 
increase of the asynchronous background discharge in the muscle (cf. F. A. Hoffmann, 1952). Such posttetanic contractions were as a rule seen only after long-lasting stimuli ( $>30 \mathrm{sec}$.); they usually subsided within 10 to 20 seconds and only with difficulty could they be counteracted by an act of will.

Most stimuli in the records in Figs. 3A and 3B were subliminal for the motor axons but in Fig. 3C a small $\mathrm{M}$-wave is present throughout the experiment. This wave does not seem to be influenced by the tetanus, a fact indicating that the antidromic motor volley in this case has also remained constant during the experiment.

POST-TETANIC DEPRESSION OF M-WAVES A marked post-tetanic depression of the $\mathrm{M}$-waves occurred only when the tetanic stimulus had a high frequency ( $>200 / \mathrm{sec}$.) and a long duration ( $>30 \mathrm{sec}$.). Fig. 4A shows how such a tetanus on the ulnar nerve affects the amplitude of the test response in the hypothenar muscles. The control stimulus applied on the ulnar nerve at the elbow was just sufficient to give a maximal $\mathrm{M}$-wave and as usual this response was followed by a small late deflection (upper record). During the first seconds of the post-tetanic period both responses were abolished and during the next 40 to 50 seconds the M-wave gradually recovered while the late deflection showed a great temporary enhancement.

Quite different results were obtained when the test stimuli were supramaximal for the motor fibres. Under these conditions there was no post-tetanic depression of the $\mathrm{M}$-wave and the amplitude of the late deflection also remained constant (Fig. 4C). This means that the $\mathrm{M}$-wave depression in Fig. 4A must be due to a post-tetanic rise of threshold in the motor fibres, which evidently recover slowly and gradually from a state of post-tetanic subnormality. (The effect was not caused by any local post-tetanic change of impedance in the tissues underlying the electrodes, for similar results were also obtained when the tetanus was applied at the elbow and the test shocks at the wrist.) It should be noted that the depression of the $\mathbf{M}$-wave is accompanied by a small increase in latency of the response (Fig. 3A), which indicates that the motor conduction velocity is lowered during the subnormal period.

The small and variable late deflection, appearing in the hypothenar muscles before the tetanus, always had a higher threshold than the M-wave and should accordingly be classified as an F-wave (Fig. 4B, upper four records). On the other hand, during the initial part of the post-tetanic period the late deflection showed the typical characteristics of an H-reflex: it had a lower threshold and often a higher amplitude than the M-wave and it was blocked by supramaximal stimuli (Fig. 4B, lower four records). During the later course of the post-tetanic period the H-reflex gradually diminished while the $M$-wave increased and finally the late deflection regained the characteristics of an F-wave. This gradual transition can be interpreted by assuming that the late deflection consists of both an $\mathrm{H}$ - and an F-component and that either of these components can show a more or less complete dominance. The present results, however, do not yield any conclusive evidence for a dual nature of the late response, and so the possibility remains that the $F$-wave is a rudimentary H-reflex almost totally blocked by the antidromic motor volley. According to this last interpretation the tetanus reveals the true nature of the F-wave by raising the threshold of the motor fibres so that weak stimuli can evoke reflexes which escape antidromic blocking. One cannot exclude that the tetanus also raises the threshold of the peripheral afferent fibres conveying the reflex but probably these fibres are affected to a lesser extent than those conveying the M-wave. The reflex often showed a small post-tetanic increase of latency (Fig. 4A) which can be fully explained by the lowered conduction velocity in the motor fibres.

The post-tetanic increase of the hypothenar reflex was probably due not only to a release from antidromic blocking, for occasionally tetanic stimuli of short duration and low frequency caused a reflex enhancement without concomitant M-wave depression (Fig. 4D). Such post-tetanic potentiation, however, was more difficult to demonstrate in the hypothenar muscles than in the other muscles investigated.

POST-TETANIC POTENTIATION OF RECIPROCAL INHIBITION ACCOMPANYING THE H-REFLEX If the Hreflex in man is analogous to the monosynaptic reflex in cats, it should be expected that it is accompanied by a reciprocal antagonist inhibition which can be potentiated in a way similar to the reflex itself (Lloyd, 1949). In order to study this problem, test shocks of maximal strength for the motor fibres were applied to the tibial nerve in the popliteal fossa while recordings were made with coaxial needle electrodes both from the soleus and the antagonistic tibialis anticus. A moderate voluntary contraction of the tibialis anticus was maintained during the whole experiment by keeping the foot in active dorsiflexion. The tibial test shocks evoked $\mathrm{M}$-waves in the soleus but usually no $\mathbf{H}$ reflexes appeared as long as the antagonistic contraction was maintained (Fig. 5A, control record, upper beam). A moderate increase of activity appeared in the tibialis anticus about $60 \mathrm{msec}$. after the shock, a reflex which could be eliminated by mechanical fixation of the foot and thus probably 
A

B

C

D

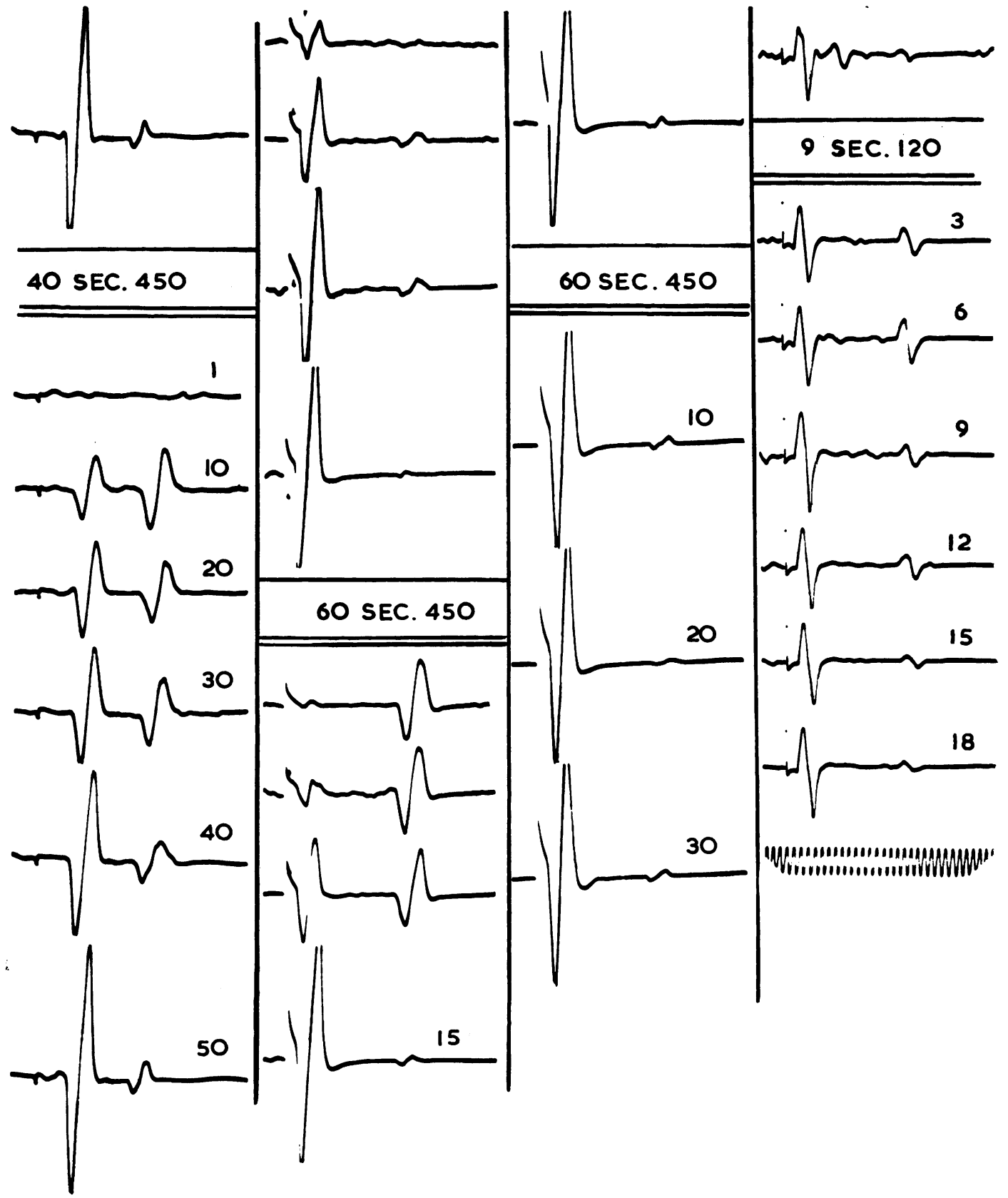

FIG. 4. Surface recording of action potentials in hypothenar muscles evoked by ulnar nerve test shocks before and after intense tetanization of the same nerve. A, test shocks (at elbow) which before tetanus are just sufficient to evoke a maximal $M$-wave. B, test shocks (above wrist) of gradually increasing strength before (upper four records) and after (lower four records) tetanus. C, test shocks (above wrist), supramaximal for the motor fibres. D, test shocks (above wrist) submaximal for motor fibres (tetanus of short duration and low frequency). Time 500/sec. 


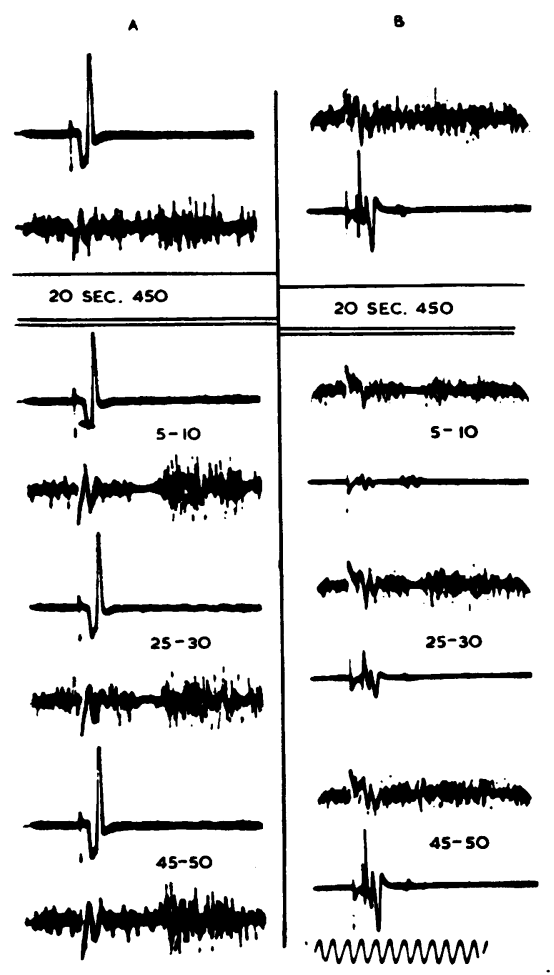

FIG. 5 . depended on the sudden plantar flexion evoked by the twitch in the calf muscles (cf. Park, Teasdall, and Magladery, 1951). In some of the individual records it seemed as if this reflex was preceded by a short inhibition but this effect never stood out clearly on the film where usually four or five records were superimposed (Fig. 5A, control record, lower beam). Tetanus on the tibial nerve was followed by a great enhancement of this early inhibition, which now appeared as a complete temporary interruption of the voluntary activity in the tibialis anticus (Fig. $5 \mathrm{~A}$, post-tetanic records, lower beams). It had a latency of about $35 \mathrm{msec}$., which corresponded quite well to the latency of the H-reflex in the soleus. The effect of the tetanus remained for 30 to $45 \mathrm{sec}$; ; at the end of this period the inhibition became progressively less distinct.

Similar results were obtained when studying the effect of peroneal nerve stimuli on voluntary activity in the soleus. Stimuli sufficient to evoke a maximal M-wave and a small reflex in the tibialis anticus had initially little or no effect on the activity in the antagonist (Fig. 5B, control record), but following a tetanus to the peroneal nerve each stimulus caused a distinct reciprocal inhibition, corresponding in time to the reflex in the tibialis anticus (Fig. 5B, post-

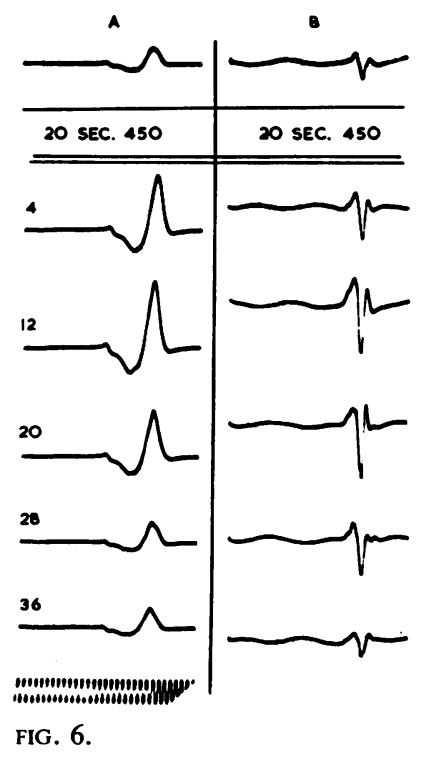

FIG. 6. A, patellar reflex (surface electrodes on quadriceps) before and after intense tetanization of femoral nerve in inguinal region. B, Achilles reflex (surface electrodes on calf muscles) before and after intense tetanization of tibial nerve in popliteal fossa. Time 500/sec.

FIG. 5. Simultaneous recording with bipolar needle electrodes from soleus (upper beam) and tibialis anticus (lower beam). A, maximal test shocks to tibial nerve in popliteal fossa before and after tetanization of the same nerve (voluntary contraction in tibialis anticus). B, submaximal test shocks to peroneal nerve at capitulum fibulae before and after tetanization of the same nerve (voluntary contraction in calf muscles). Four or five beams superimposed in each record. Time 100/sec. tetanic records). In the experiment illustrated by Fig. 5 the tetanus also caused a depression of the M-wave in the tibialis anticus and possibly an early slight enhancement of the reflex. The latter effect may be due partly to a release from antidromic motor blocking but the enhancement of the antagonistic inhibition can apparently not be explained in a similar way. The short latency of the reciprocal inhibition indicates that it is induced by an afferent volley in peroneal afferent fibres with high conduction velocity. As might be expected, it was found that the inhibition appeared in a similar way when the peroneal nerve had been totally blocked by xylocaine distal to the stimulating electrode.

POST-TETANIC POTENTIATION OF MECHANICALLY EVOKED STRETCH REFLEXES As shown in Fig. 6A, a tetanic stimulation of the femoral nerve was followed by a potentiation of the patellar reflex as recorded with surface electrodes from the quadriceps muscle. The technique did not allow precise measurements of the time course of this potentiation for the amplitude of the reflex often showed great random changes, due mainly to the inconstancy of the mechanical stimulus. Usually, however, the potentiation reached a maximum within $10 \mathrm{sec}$. and then 
gradually subsided. It appeared not only as an increase of the muscle potential but also as an obvious enhancement of the reflex movement. It was difficult to exclude, however, that this latter effect was partly due to a potentiation of purely muscular origin (Brown and von Euler, 1938; Botelho and Cander, 1953). When the tetanic stimulus was applied to other nerve trunks in the body it did not cause any enhancement of the patellar reflexes, indicating that the potentiation was not due to a general arousal effect resulting in a nonspecific sensitization of muscle spindles. A tetanic stimulation of the tibial nerve caused a temporary enhancement of the Achilles reflex (Fig. 6B) but did not appreciably affect the patellar jerk.

\section{DISCUSSION}

Post-tetanic potentiation refers to a state of longlasting facilitation of presynaptic origin, which is common to most synaptic junctions so far examined in animal experiments (for references, see Hughes, 1958). The phenomenon has been found in the spinal cord where it appears more potent in monosynaptic than in polysynaptic paths, in various subcortical nuclei and in the neuromuscular, sympathetic, auditory, visual, and olfactory systems. It has been suggested that post-tetanic potentiation plays a major role in the physiology of the nervous system, possibly in the sphere of perception and learning (Eccles, 1953) and also at the spinal level where evidence exists for a connexion between posttetanic perception and such phenomena as temporal summation, rebound, and spasticity (Granit, 1956).

Experiments in man (Botelho, 1955; Botelho and Cander, 1953) have shown that tetanization of a muscle nerve may be followed by a long-lasting increase of the mechanical muscle twitch, a potentiation which apparently is of muscular origin since it is not accompanied by a corresponding increase of the muscle potential (cf. Brown and von Euler, 1938). A neuromyal potentiation appearing as an increase of the muscle potential has been demonstrated in patients with myasthenia gravis (Johns et al., 1955), and according to Hughes and Morrell (1957), this effect is also occasionally seen in normal subjects when using submaximal test stimuli. F. A. Hoffmann's experiments indicate that post-tetanic perception also exists in the human central nervous system (1952), but he emphasized that the posttetanic increase of the H-reflexes in man was quite small as compared with the potentiation of monosynaptic reflexes in cats. In the present study, the H-reflexes often showed a post-tetanic enhancement of more than $100 \%$, an effect fully comparable with that in cats (Lloyd, 1949). This discrepancy between Hoffmann's and our results may be due to the fact that we regularly used more intense tetanic stimuli.

The central origin of the potentiation described can hardly be doubted, since the reflex muscle potential was often greatly enhanced without any alteration of the amplitude of the M-wave, and also since the potentiation involved not only the excitatory but also the central inhibitory effect of the afferent volley on antagonistic motoneurones. The enhancement of the reflex was not dependent on a post-tetanic facilitatory contraction for the enhancement often occurred without an increase of asynchronous activity and furthermore the maximal facilitation obtainable by voluntary contraction was often small compared with the large enhancement during the post-tetanic period. Thus, the potentiation of the H-reflex is probably analogous to the post-tetanic potentiation of the monosynaptic reflex in animals, which is explained in terms of increased pre-synaptic action due to changes in afferent terminal fibres (Lloyd, 1949, 1959) or in synaptic boutons (Eccles, 1953; Eccles and Rall, 1951).

Additional problems are encountered in those experiments where a post-tetanic enhancement of the H-reflex was accompanied by a change in amplitude of the M-wave. A post-tetanic increase of the M-wave was never seen and consequently the enhancement of the reflex was in no instance due to neuro-myal potentiation. The post-tetanic depression of the M-wave occurring after intense tetanic stimulation has been described in man by Hughes and Morrell (1957) who suggested that this subnormality may be related to the accumulation of lactic acid in the muscle. The present experiments showed, however, that the M-wave depression did not occur when supramaximal test stimuli were used, which indicates that the effect is due to a rise in threshold of the motor nerve fibres. Consequently the depression of the $\mathrm{M}$-wave is probably accompanied by a similar depression of the antidromic motor volley and so the post-tetanic reflex enhancement in these experiments can be explained not only as pre-synaptic potentiation but also as a release from the blocking effect of the antidromic motor discharge. It may be expected that there is also a post-tetanic subnormality in the peripheral afferent fibres mediating the reflex but either this subnormality is negligible or it is totally concealed by those mechanisms which bring about the actual reflex enhancement.

The potent post-tetanic potentiation of the $\mathrm{H}$ reflex represents a further similarity between this reflex and the monosynaptic reflex in cats, but on the other hand the results do not contradict the opinion of Magladery and Teasdall (1958) that polysynaptic 
paths may also contribute to the H-response. The nature of the F-wave is more debatable. The present results show that it is often possible to change an F-wave into a typical H-reflex by either of the following manoeuvres: 1 A voluntary contraction of the muscle which probably raises the excitability of the motoneurones responding to the afferent volley; 2 preceding tetanus on the muscle nerve, which probably raises the excitatory action of presynaptic structures and also tends to diminish the blocking antidromic motor volley. The results do not permit any definite conclusions about the ultimate nature of the F-wave but it seems that further experiments are needed before it can be ruled out that it is merely a rudimentary H-reflex, lacking pre- or post-synaptic facilitation and/or partially blocked by the antidromic motor volley.

Ström (1951) concluded from his experiments on post-tetanic potentiation in cats that the stretch reflex is not potentiated to a degree quantitatively comparable to the simultaneous potentiation of the monosynaptic reflex elicited by an afferent test shock: and, further, it proved impossible to produce a change identical with post-tetanic potentiation by intense afferent activity elicited by physiological mechanisms. F. A. Hoffmann's experiments in man gave similar results (1952). In a single unit analysis of reflexes in the ventral roots, Granit (1956) showed, however, that tetanization and/or stretch create a long-lasting state of post-tetanic potentiation or hypersensitivity to subsequent test reflexes. The present experiments showed that the stretch reflex could be potentiated in a way similar to the H-reflex but the experimental conditions did not allow any precise quantitative comparisons as regards the duration or intensity of these post-tetanic events. Preliminary attempts were made to find out if a forceful and long-lasting voluntary contraction was followed by a potentiation of the H-reflexes but the results were negative.

So far, no attempts have been made to study posttetanic potentiation of the myotatic reflex in spastic or rigid patients, but such an investigation seems justified since animal experiments indicate a correlation between post-tetanic potentiation and states of spasticity (Granit, 1956). It would also be of interest to know if post-tetanic potentiation in man can be used as a tool to differentiate between tonic and phasic motoneurones in a way similar to that employed in cats (Granit, Henatsch, and Steg, 1956; Granit, Phillips, Skoglund, and Steg, 1957). In this connexion, the post-tetanic asynchronous muscle discharge deserves special attention, since it may be postulated that it represents activity in tonic ventral horn cells.

\section{SUMMARY}

Myotatic reflexes evoked by tendon taps or by single nerve shocks (H-reflexes) were recorded with surface or needle electrodes from various muscles in the extremities. The soleus muscle was found to be exceptional because of its high amplitude $\mathrm{H}$-reflexes; in other muscles the reflexes were smaller and often appeared only during the facilitatory influence of a voluntary contraction.

H-reflexes elicited by nerve shocks subliminal for motor axons could be potentiated by tetanic stimulation of the motor nerve. A tetanus of 100 to $500 /$ sec. lasting about $20 \mathrm{sec}$. was often followed by reflex enhancement which showed a maximum within five to $10 \mathrm{sec}$. and then gradually subsided during 30 to $40 \mathrm{sec}$.

A similar potentiation was also observed when the test shocks were supraliminal for the motor axons but in this case the indirect motor response often showed post-tetanic depression and it seemed likely that the reflex enhancement was partly due to release from blocking antidromic impulses in motor axons. The F-waves normally seen in small hand muscles changed into typical $\mathrm{H}$-reflexes during the period following the tetanus.

The H-reflex in the calf muscles was accompanied by weak and variable reciprocal inhibition of voluntary activity in the antagonistic peroneal muscles. After a tetanic stimulus to the tibial nerve this reciprocal inhibition was greatly enhanced and showed a potentiation curve similar to that of the H-reflex. Post-tetanic potentiation of mechanically evoked stretch reflexes (Achilles and patellar reflexes) followed a similar time course and appeared as a marked enhancement not only of the evoked muscle potential but also of the reflex movement.

\section{REFERENCES}

Botelho, S. Y. (1955). J. clin. Invest., 34, 1403.

- and Cander, L. (1953). J. appl. Physiol., 6, 221.

Brown, G. L., and Euler, U. S. von (1938). J. Physiol. (Lond.), 93, 39. Dawson, G. D., and Merton, P. A. (1956). XX Int. Congr. Physiol., Brussels, 1956. Abstracts of Communications, p. 221.

Denny-Brown, D. (1929). Proc. roy. Soc. B., 104, 252.

Eccles, J. C. (1953). The Neurophysiological Basis of Mind: The Principles of Neurophysiology. Clarendon Press, Oxford.

-, Eccles, R. M., and Lundberg, A. (1957). J. Physiol. (Lond.), $137,22$.

—, and Rall, W. (1951). J. Neurophysiol., 14, 353.

Granit, R. (1955). Receptors and Sensory Perception, Yale University Press, New Haven.

(1956). J. Physiol. (Lond.), 131, 32.

-, Henatsch, H. D., and Steg, G. (1956). Acta physiol. scand., 37, 114.

—, Phillips, C. G., Skoglund, S., and Steg, G. (1957). J. Neurophysiol., 20, 470.

Hoffmann, F. A. (1952). Pflüg. Arch. ges. Physiol., 255, 308.

Hoffmann, P. (1918). Z. Biol., 68, 351.

- (1922). Untersuchungen über die Eigenreflexe (Sehnenreflexe) menschlicher Muskelin. Springer, Berlin.

(1952). Experientia (Basel), 8, 371.

- , and Keller, C. J. (1928). Z. Biol., 87, 327, 527. 
Hughes, J. R. (1958), Physiol. Rev., 38, 91.

, and Morrell, R. M. (1957). J. appl. Physiol., 11, 51.

Johns, R. J., Grob, D., and Harvey, A. M. (1955). Amer. J. Med., 19, 679.

(1957). Bull. Johns Hopk. Hosp., 101, 232.

Lloyd, D. P. C. (1943). J. Neurophysiol., 6, 317.

(1946). Ibid., 9, 439.

(1949). J. gen. Physiol., 33, 147.

(1959). Ibid., 42, 475.

Magladery, J. W., and McDougal, Jr. D. B. (1950). Bull. Johns Hopk. Hosp., 86, 265.
-, Porter, W. E., Park, A. M., and Teasdall, R. D. (1951). Ibid., 88, 499.

- and Teasdall, R. D. (1958). Ibid., 103, 236.

Paillard, J. (1955). Pflüg. Arch. ges. Physiol., 260, 448.

Park, A. M., Teasdall, R. D., and Magladery, J. W. (1951). Bull. Johns Hopk. Hosp., 88, 549.

Schenck, E. (1951). Pflüg. Arch. ges. Physiol., 253, 286.

Ström, G. (1951). Acta physiol. scand., 24, 61.

Teasdall, R. D., Park, A. M., Languth, H. W., and Magladery, J. W. (1952). Bull. Johns Hopk. Hosp., 91, 245.

Thomas, J. E., and Lambert, E. H. (1960). J. appl. Physiol., 15, 1. 